\title{
Investigating the Creep Behavior of Marine Soft Structured Clay by FEM with an Elasto-viscoplastic Constitutive Model
}

\author{
M.J. Jiang ${ }^{* * *}$, C.O Woyeya ${ }^{1}$, J. Liu ${ }^{1}$ \\ ${ }^{1}$ Department of Civil Engineering, Tianjin University, 135 Yaguan Road, \\ Tianjin 300350, China \\ *Corresponding author: mingjing.jiang@tju.edu.cn
}

\begin{abstract}
The time-dependent creep deformation of marine soft-structured clay is a major cause for foundation failure for structures built on soft grounds around the globe. This study focuses on the analysis of the drained and undrained time-dependent creep behavior of a normally consolidated (NC)-Kyuhoji marine soft-structured clay by FEM with a new Elasto-viscoplastic (EVP) constitutive model. Onedimensional creep and consolidated undrained creep element tests are simulated to analyze the creep behavior of soft clay under constant loading conditions. The creep period of 1157 days is used in the drained state with consolidation pressures from $100 \mathrm{kPa}$ to $450 \mathrm{kPa}$ with $50 \mathrm{kPa}$ incremental intervals. The undrained time-dependent creep behavior of Kyuhoji clay is analyzed under different constant creep stresses- $q_{c r p}\left(0.3 q_{f}, 0.5 q_{f}, 0.6 q_{f}\right.$, and $0.7 q_{f}$, where $q_{f}$ is the undrained peak strength), and creep periods (11.6days, 463days, and 5787 days). The results show that: (1) In the case of the drained state, the secondary compression index, $C_{\alpha}$ initially decreases with increasing consolidation pressure up to pre-consolidation pressure- $\sigma_{c}$, and becomes constant for consolidation pressures above $\sigma_{c}$. (2) For small consolidation pressures $(<150 \mathrm{kPa}), C_{\alpha}$ initially decreases with time, then becomes constant. (3) In an undrained state with a constant load, soft marine clay is seen to initially experience creep hardening, then softening due to an increase in excess pore water pressure at constant load up to failure of the soil. (4) The rate of excess pore water pressure development under constant load is highly dependent on the magnitude of creep stress- $q_{c r p}$. These results have shown the capability of the new EVP-model in analyzing creep failure which can explain the premature abrupt collapse of foundations on softstructured clay soils where drainage is impeded under constant load.
\end{abstract}

Key words: Elasto-viscoplastic Constitutive model, Creep behavior, Marine soft-structured clay,Drained condition, Undrained condition, Element analysis.

\section{REFERENCES}

[1] Wang, Z., Jiang, M.J., Shen, Z., Chen, S. and Cai, J. A new method for establishing elasticviscoplastic constitutive model of clay. Geomechanics from Micro to Macro, K. Soga, K. Kumar, G. Biscontin, and M. Kuo (2014):699-704.

[2] Zhao, X., Wang, Q., Gao, Y., Yang, T., He, L., and Lu, X. Indoor Rheological Test and Creep Model Analysis of Soft Soil in Qingyi River region in Wuhu Anhui. IOP Conf. Ser.: Earth Environ. Sci.(2019)330.

[3] Fatahi, B., Le, T.M., Le, M.Q., and Khabbaz, H. Soil creep effects on ground lateral deformation and pore water pressure under embankments. Geomechanics and Geoengineering (2013)8:107-124.

[4] Grimstad, G., Minna, K., Hans, P.J., Nallathanmby, S., Magne, M., Cor, Z., Haan, E., and Seyed, A.G. Creep of geomaterials - some finding from the EU project CREEP. European Journal of Environmental and Civil Engineering (2017):1-16.

[5] Long, Z., Cheng, Y., Yang, G., Yang, D., and Xu, Y. Study on Triaxial Creep Test and Constitutive Model of Compacted Red Clay. Int J Civ Eng (2020).

[6] Zhu, J.G., Zhao, Y.H., and Yin, J.H. Undrained Creep Behavior of a Silty Clay in Triaxial Tests. Instrumentation, Testing, and Modeling of Soil and Rock Behavior-Hunan, China (2011):139-146. 